Check for updates

Cite this: RSC Med. Chem., 2020, 11, 833

Received 15th April 2020,

Accepted 21st May 2020

DOI: $10.1039 / \mathrm{dOmd00123f}$

rsc.li/medchem

\section{An investigation of the antileishmanial properties of semi-synthetic saponins $\dagger$}

\author{
Orlagh Anderson, $\mathbb{D} \dagger^{\mathrm{a}}$ Joseph Beckett, $t^{\mathrm{a}}$ Carla C. Briggs, $\ddagger^{\mathrm{a}}$ Liam A. Natrass, ${ }^{\text {ab }}$ \\ Charles F. Cranston, (D) ${ }^{a}$ Elizabeth J. Wilkinson, ${ }^{c}$ Jack H. Owen, ${ }^{c}$ \\ Rhodri Mir Williams, ${ }^{c}$ Angelos Loukaidis, ${ }^{c}$ Marc E. Bouillon, (D) ${ }^{c}$ Deiniol Pritchard, ${ }^{d}$ \\ Martina Lahmann, (iD ${ }^{c}$ Mark S. Baird (iD ${ }^{d}$ and Paul W. Denny (DD ${ }^{* a}$
}

\begin{abstract}
Leishmaniasis is a neglected tropical disease caused by insect-vector borne protozoan parasites of the, Leishmania species. Whilst infection threatens and affects millions of the global poor, vaccines are absent and drug therapy limited. Extensive efforts have recently been made to discover new leads from small molecule synthetic compound libraries held by industry; however, the number of new chemical entities identified and entering development as anti-leishmanials has been very low. This has led to increased interest in the possibility of discovering naturally derived compounds with potent antileishmanial activity which may be developed towards clinical applications. Plant-derived triterpenoid and steroidal saponins have long been considered as anti-microbials and here we describe an investigation of a library of 137 natural (9) and semi-synthetic saponins (128) for activity against Leishmania mexicana, a causative agent of cutaneous leishmaniasis. The triterpenoid sapogenin, hederagenin, readily obtained in large quantities from Hedera helix (common ivy), was converted into a range of 128 derivatives. These semi-synthetic compounds, as well as saponins isolated from ivy, were examined with a phenotypic screening approach to identify potent and selective anti-leishmanial hits. This led to the identification of 12 compounds, including the natural saponin gypsogenin, demonstrating high potency $\left(E D_{50}<10.5 \mu M\right)$ against axenic $L$. mexicana amastigotes, the mammalian pathogenic form. One of these, hederagenin disuccinate, was sufficiently non-toxic to the macrophage host cell to facilitate further analyses, selectivity index (SI) $>10$. Whilst this was not active in an infected cell model, the anti-leishmanial properties of hederageninderivatives have been demonstrated, and the possibility of improving the selectivity of natural hederagenin through chemical modification has been established.
\end{abstract}

\section{Introduction}

Leishmaniasis is one of the 20 neglected tropical diseases (NTD), and is endemic in over 90 countries, affecting approximately 12 million people per year, with over one billion people living at risk of disease. ${ }^{1}$ Causative Leishmania species are sand fly borne kinetoplastid protozoan parasites $^{2}$ with

\footnotetext{
${ }^{a}$ Department of Biosciences and Centre for Global Infectious Diseases, Durham University, Stockton Road, Durham, DH1 3LE, UK.

E-mail: p.w.denny@durham.ac.uk; Tel: +44 (0)1913343983

${ }^{b}$ Department of Chemistry and Centre for Global Infectious Diseases, Durham University, Stockton Road, Durham, DH1 3LE, UK

${ }^{c}$ Department of Chemistry, School of Natural Science, Bangor University, Gwynedd, LL57 2UW, UK

${ }^{d}$ Naturiol Bangor Ltd, Alun Roberts Building, Bangor University, Gwynedd, LL57 $2 U W, U K$

$\dagger$ Electronic supplementary information (ESI) available. See DOI: 10.1039/ d0md00123f

$\$$ Contributed equally to the work.
}

infection leading to a wide spectrum of disease, from selfhealing but scarring cutaneous leishmaniasis (CL) to fatal visceral disease (VL). The diversity of disease is dependent on the parasite species, genetic background and host immunity. ${ }^{3}$ Driven by elimination efforts in south Asia, the global burden of VL has decreased substantially in the past decade. However, in the same time period, CL cases have increased dramatically (0.7-1.0 million per year) largely due to forced migration in conflict zones. ${ }^{4}$ Against this backdrop, no vaccine is available and treatment relies entirely on a limited number of less than ideal drugs. Recently, public-private partnerships have seen industrial scale $(>1000000)$ compound libraries screened for anti-leishmanials either phenotypically ${ }^{5,6}$ or target-based. ${ }^{7}$ All these initiatives focused on VL, leaving the most common form of leishmaniasis, CL, as a neglected NTD. Treatment of CL largely relies on the pentavalent antimonials - sodium stibogluconate (Pentostam) and meglumine antimoniate (Glucantime). ${ }^{8,9}$ Both drugs have been in clinical use for over 70 years despite their severe side-effects, ${ }^{10}$ parenteral 
administration, ${ }^{11}$ and the emergence of drug resistance. ${ }^{12}$ Diamidine pentamidine ${ }^{13}$ and amphotericin B (Fungizone) ${ }^{14}$ are second-line CL drugs, but are similarly associated with severe side-effects and Leishmania resistance has been observed under laboratory conditions. ${ }^{15}$

The severe issues with the drugs used to treat CL demand the discovery and development of new effective therapies. Natural products are the basis of traditional 'folk' therapies, including for leishmaniasis. ${ }^{16,17}$ The active compounds from these include chalcones, ${ }^{18-21}$ flavonoids, ${ }^{22,23}$ alkaloids ${ }^{24}$ and terpenoids. $^{25,26}$ Further, the anti-leishmanial amphotericin B is a natural product polyene, which was isolated from Streptomyces nodosus as an antifungal in $1955 .{ }^{27}$ With reference to this history, it is logical to revisit the natural world in the search for much needed anti-leishmanials. ${ }^{28}$

Saponins are a diverse class of compounds produced by many plants, and some marine organisms, via the mevalonic acid pathway. They consist of an aglycone unit (sapogenin) linked to between one and three carbohydrate moieties. ${ }^{29,30}$ Depending on the nature of the sapogenin, saponins are divided into two main classes - triterpenoid and steroidal. Triterpenoid saponins mainly occur in dicotyledonous angiosperms and comprise sapogenin moieties of six isoprene units, usually arranged as five rings, and bear structurally diverse carbohydrate groups. ${ }^{31}$ The less varied and widespread steroidal saponins consist primarily of a fivering furostane or a six-ring spirostane skeleton and are almost exclusively produced by monocotyledonous angiosperms. $^{32}$ The structural diversity of saponins is associated with a wide range of bioactivities. As secondary metabolites, their role in plants lies primarily in protection from herbivory and pathogen attack. ${ }^{29}$ However, saponins also possess a variety of pharmaceutical properties, from anti-inflammatory and anti-cancer to vaccine adjuvant activity. ${ }^{33,34}$ Several previous studies have identified saponins with anti-leishmanial activity. ${ }^{35-51}$

The beneficial effects of extracts from Hedera helix (common ivy), and in some cases of the discrete saponins extracted, have been widely reported. These include antiinflammatory properties, ${ }^{52-54}$ anti-asthma activity ${ }^{55,56}$ and applications in cough medicines. ${ }^{57}$ More recently, anti-viral ${ }^{58}$ and anti-cancer properties ${ }^{20,59}$ have been reported. Extracts also show potent anti-fungal properties, ${ }^{60,61}$ but of particular interest were the reports of anti-leishmanial saponins extracted from $H$. helix. ${ }^{36,43,50,53,62}$ Extracted and purified monodesmoside triterpenoid saponins ( $\alpha$-, $\beta$ - and $\delta$-hederin) demonstrated activity against both promastigote (insect stage) and intracellular amastigote (mammalian stage) forms of both L. tropica and L. infantum. ${ }^{43}$

The saponins of common ivy are primarily based on a triterpene skeleton, hederagenin (Fig. 1), in which the alcohols or the acid are linked to sugars. Base hydrolysis on isolation of the saponins leads to the removal of the acidbound sugars, and acid hydrolysis to the removal of all sugars. It is possible to isolate large quantities of saponins from both ivy leaf and fruit, ${ }^{63}$ based primarily on a single

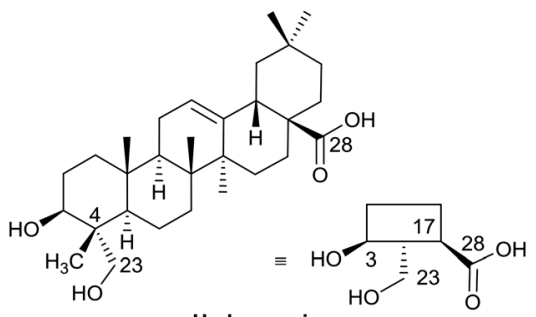

Hederagenin

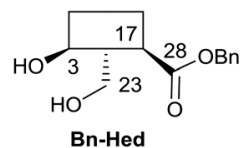

Fig. 1 Short-hand structures for hederagenin and its benzyl ester (BnHed) with relevant numbering.

sapogenin, hederagenin. It is therefore of interest to determine whether the biological activity of these saponins, and of hederagenin, can be optimised by simple chemical modification to provide novel, plant based, solutions for application in medicine or agriculture. As part of a wider study of chemically modified saponins, we now describe the evaluation of the anti-leishmanial effects of 128 semisynthetic molecules obtained by modification of the hederagenin core, together with nine natural product controls isolated from ivy extracts.

\section{Results and discussion}

\section{Compound screening scheme}

The library of hederagenin based compounds (137), either isolated from Hedera helix or synthesised from hederagenin obtained by extraction and hydrolysis of ivy saponins, were screened as illustrated in Fig. 2.

All available compounds were subjected to a primary screen against mammalian stage $L$. mexicana axenic amastigotes as described below. These data and the structures of all compounds tested are provided in the ESI $\dagger$ (Table S1). Compounds that achieved $\geq 95 \%$ inhibition were taken forward to a secondary dose response screen which identified 12 highly active compounds for further examination.

\section{Syntheses of compounds taken forward to the toxicity screen}

The syntheses of key compounds, those 12 taken through to toxicity screening (Fig. 2) and not described elsewhere, are reported here (NMR data in ESI $\dagger$ ). The 3,23-O-isopropylidene protected hederagenin MC-014 (ref. 64) was converted into the corresponding isocyanate (MC0-15) by a standard method. This intermediate was converted into a large number of derivatives (Table S1 $\dagger$ ). In particular, MC-033 and MC0-57 were prepared respectively by reaction with L-proline, or with pyrrolidine followed by hydrolysis (Scheme 1).

Hederagenin methyl ester $(\mathbf{1})^{65}$ was converted into a series of 2,23-O-acetal derivatives, including, after ester hydrolysis, MC-071 (Scheme 2). 


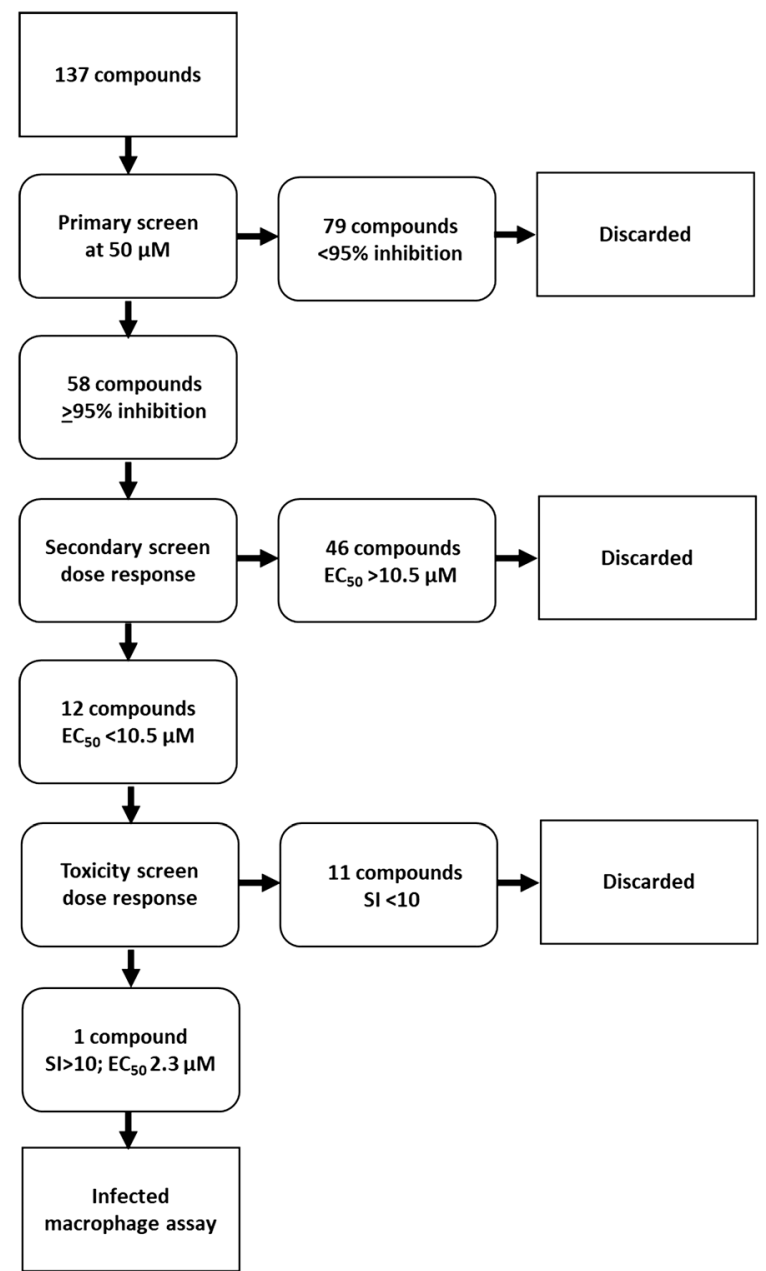

Fig. 2 Screening scheme applied to compound library.

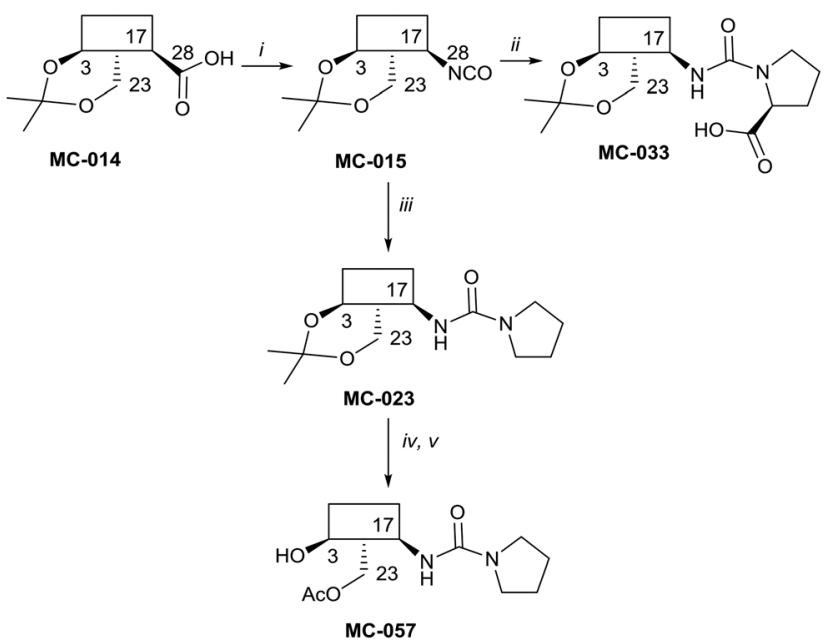

Scheme 1 i. DPPA, $\mathrm{Et}_{3} \mathrm{~N}$, tol, $90{ }^{\circ} \mathrm{C}, 80 \%$; ii. L-proline, EtOH, reflux to rt, quant.; iii. pyrrolidine, tol, $88 \%$; iv. $\mathrm{HCl}(\mathrm{aq}), \mathrm{DCM} / \mathrm{H}_{2} \mathrm{O}$, quant; v. $\mathrm{AcCl}, \mathrm{DMAP}, \mathrm{Et}_{3} \mathrm{~N}$, tol, $5^{\circ} \mathrm{C}, 56 \%$.

Anemoclemosides $^{66}$ are natural products featuring a unique open chain sugar moiety, linked to the sapogenin through an 3,23-O-acetal. However, they share the same

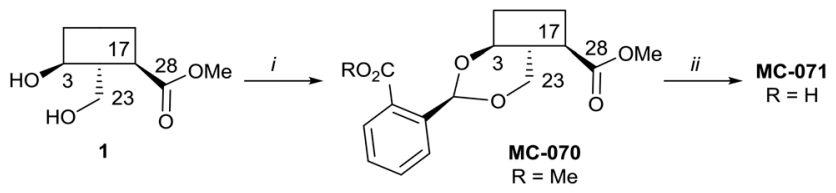

Scheme 2 i. Methyl 2-formylbenzoate, PTSA (cat), DCM, quant.; ii. $\mathrm{LiOH} ; \mathrm{THF} / \mathrm{MeOH} / \mathrm{H}_{2} \mathrm{O}(4: 1: 1), 65^{\circ} \mathrm{C}, 86 \%$.

common hederagenin aglycone. In this work a series of anemoclemosides (Table S1 $\dagger$ ), including the natural compound anemoclemoside $\mathrm{A},{ }^{64}$ were prepared from hederagenin. The total synthesis of this series of compounds will be described elsewhere (Lahmann and Bouillon, in preparation), but many of them have been screened in this work. The key compound IVL-81 was prepared by peracetylation of anemoclemoside A (Scheme 3).

With the intention of removing the enzymatically cleavable glycosidic linkage and thus increase in vivo stability, a series of $C$-glycosides was also prepared (Table $\mathrm{S} 1 \dagger)$. As an alternative, acetal formation via the oxidised 6-position of monosaccharides was also performed. The key compound IVL-106 was obtained after oxidation ${ }^{67}$ of the tri$O$-benzyl protected methyl glucoside 2 to the corresponding aldehyde 3, followed by acetal formation with Bn-Hed (Fig. 1) to give 4, and subsequent global deprotection (Scheme 4).

While the sugars in most natural saponins occur in their pyranose form, it was of interest to evaluate a derivative with a furanosyl residue. Thus, IVL-104 was prepared from an L-fucose derived propenyl derivative 5 by oxidation, ${ }^{68}$ prior to acetal formation with Bn-Hed and global deprotection (Scheme 5). Since it was not possible to separate the pseudo anomers at any step of the synthesis, the diastereomeric mixture was used for biological evaluation.

Gypsogenin (IVL-9) is a saponin closely related to hederagenin, ${ }^{69}$ and for this work, it was synthesised from hederagenin by a protection, oxidation deprotection sequence (Scheme 6).

\section{Screening of modified and natural saponins}

Primary screening. Utilising a 96-well protocol previously developed to identify anti-leishmanial compounds ${ }^{70}$ the hederagenin library was tested in a preliminary screen against mammalian stage $L$. mexicana axenic amastigotes at $50 \mu \mathrm{M}$ in duplicate (137 compounds, Fig. 2 and Table S1†). An appropriate positive control (amphotericin B) was selected and the robustness of the platform indicated by $Z^{\prime}$ values

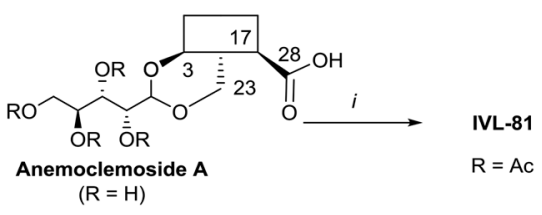

Scheme 3 i. $\mathrm{Ac}_{2} \mathrm{O}$, pyridine, $90{ }^{\circ} \mathrm{C}, 95 \%$. 

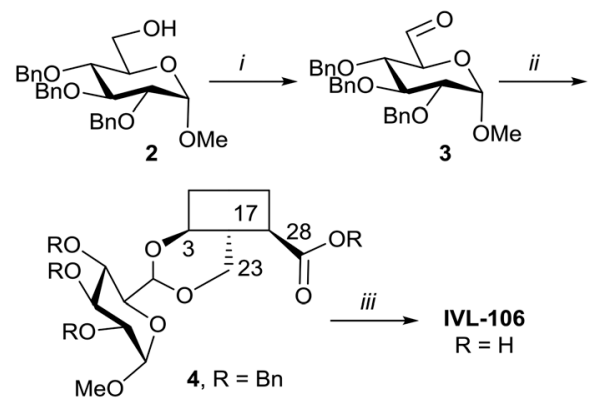

Scheme 4 i. $(\mathrm{COCl})_{2}, \mathrm{Et}_{3} \mathrm{~N}, \mathrm{DMSO} / \mathrm{DCM},-78{ }^{\circ} \mathrm{C}, 87 \%$; ii. Bn-Hed, PTSA (cat), DCM, 78\%; iii. $\mathrm{Pd}(\mathrm{OH})_{2} / \mathrm{C}, \mathrm{H}_{2}, \mathrm{MeOH} / \mathrm{MTBE}, 92 \%$.
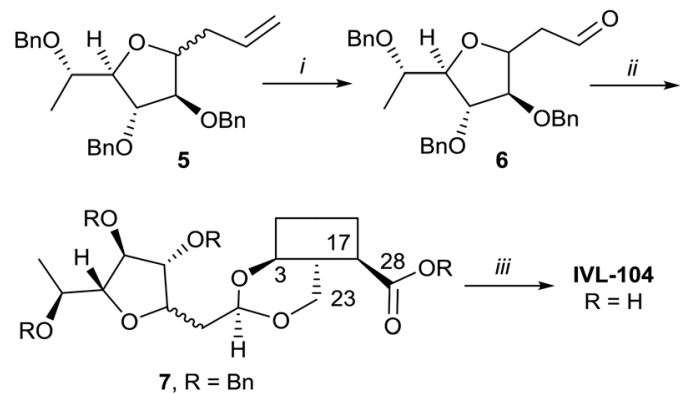

Scheme 5 i. $1 . \mathrm{O}_{3}, \mathrm{DCM}-75{ }^{\circ} \mathrm{C}, 2 . \mathrm{PPh}_{3}, 75 \%$; ii. $\mathrm{Bn}$-Hed, PTSA (cat), DCM, $95 \%$; iii. $\mathrm{Pd}(\mathrm{OH})_{2} / \mathrm{C}, \mathrm{H}_{2}, \mathrm{MeOH} / \mathrm{MTBE}, 80 \%$.

$>0.5 .^{71} 58$ compounds (Fig. 2 and Table $\mathrm{S} 1, \dagger$ highlighted yellow), inhibited amastigote proliferation $\geq 95 \%$. The excluded compounds included natural hederagenin $(<80 \%$ inhibition; red in Table S1 $\dagger$ ), with 60 of the derivatives less active than the cut-off, as well as 19 showing no activity at all (blue in Table $\mathrm{S} 1 \dagger$ ). Several other naturally occurring saponins were represented in the library. $\alpha$ - and $\delta$-hederins (IVL-11 and IVL-13), which have been reported to be active against Leishmania spp were inhibitory above the threshold, as was gypsogenin (IVL-9) and hederoside B (IVL-12). In contrast, oleanolic acid (IVL-8), hederoside F (IVL-14) and hederacoside D (IVL-15) fell below the threshold (Table S1 $\dagger$ ).

Secondary screening and toxicity testing. The 58 selected compounds were taken forward into dose response screening
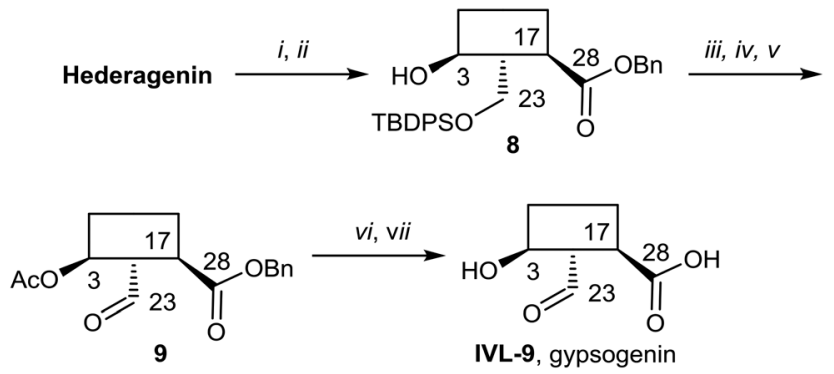

Scheme 6 i. $\mathrm{BnBr}, \mathrm{K}_{2} \mathrm{CO}_{3}, \mathrm{DMF}, 25{ }^{\circ} \mathrm{C}, 75 \%$ (S1); ii. TBDPSCl, imidazole, $\mathrm{DCM}, \mathrm{O}^{\circ} \mathrm{C}$ to $\mathrm{rt}$, quant. (S1); iii. $\mathrm{Ac}_{2} \mathrm{O}$, pyridine, $\mathrm{DCM}$, rt to $90{ }^{\circ} \mathrm{C}, 95 \%$; iv. TBAF/AcOH, THF, $50{ }^{\circ} \mathrm{C}$ to $100{ }^{\circ} \mathrm{C}, 27 \%$; v. TEMPO, BAIB, DCM, $67 \%$; vi. $\mathrm{NaOH}, \mathrm{DME} / \mathrm{THF} / \mathrm{H}_{2} \mathrm{O}, 25{ }^{\circ} \mathrm{C}, 83 \%$; vii. $\mathrm{Pd}(\mathrm{OH})_{2} / \mathrm{C}$, $\mathrm{H}_{2}, \mathrm{MeOH} / \mathrm{EtOAC}, 80 \%$. to give the $\mathrm{ED}_{50}$ against axenic $L$. mexicana as described in the ESI $\dagger$ (Fig. 2 and Table 1, columns 3 and 4). Ten of these compounds demonstrated $\mathrm{EC}_{50} \leq 10 \mu \mathrm{M}$, the industry standard for anti-leishmanial development, ${ }^{7}$ including IVL-9 (gypsogenin). Two additional compounds with $\mathrm{ED}_{50}<10.5 \mu \mathrm{M}$ were also retained. Eleven of these twelve compounds demonstrated $\mu \mathrm{M}$ activity against the Leishmania amastigotes (ED ${ }_{50}$ 2.3-10.4 $\mu \mathrm{M}$ ); however, only MC-033 had sub- $\mu \mathrm{M}$ efficacy, with an $\mathrm{ED}_{50}$ of $0.9 \mu \mathrm{M}$. Subsequently, the 12 hits (green in Table 1, columns 1-3) were taken forward to cytotoxicity screening against RAW 267.4 macrophages (Fig. 3 and Table 1, columns 5 and 6). All compounds with $\mathrm{ED}_{50}$ against host cells $\leq 10 \mu \mathrm{M}$ were excluded as toxic as were all those that demonstrated a selectivity index (SI) with respect to macrophages and axenic amastigotes $\leq 10$ (red in Table 1). ${ }^{7}$ This triage process excluded 11 compounds, including the highly active MC-033 (red in Table 1), leaving only IVL-1 (hederagenin disuccinate) (Fig. 3); axenic amastigote $\mathrm{ED}_{50}=2.3$ $\mu \mathrm{M}$; RAW 267.4 $\mathrm{ED}_{50}>100 \mu \mathrm{M}$; SI $>43.5$.

Previous analyses of the anti-leishmanial activity of isolated and purified hederagenins (including $\alpha$-hederin and related hederin and hederacoside molecules) demonstrated that they are membrane disruptors of all life cycle stages of the parasite, but also exert similar activity against mammalian cells leading to toxicity. ${ }^{36,50}$ Similar toxicity issues have been noted with respect to anti-leishmanial peptides and peptoids which are both classes of membrane disrupter. ${ }^{70,72-75}$ Therefore, the ability to modify hederagenin to form non-toxic, yet anti-leishmanial, hederagenin disuccinate (IVL-1; Fig. 3) is an important finding. However, although the axenic amastigote screen was performed with the clinically relevant parasite stage, this assay has limitations. Drug penetration of the host cell is not evaluated, neither is activity in the phagolysosomal environment in which the parasite resides. ${ }^{76}$ Previous studies have reported a lack of correlation between compounds selected in axenic form screening and intracellular amastigote assays. ${ }^{77}$ Therefore, IVL-1 (hederagenin disuccinate) was taken forward to an infected cell assay (Fig. 2 and Table 1, columns 8 and 9). Unfortunately, while passing all initial screens, IVL-1 was inactive in the infected cell assay $\left(\mathrm{ED}_{50}>50 \mu \mathrm{M}\right)$, that is against Leishmania amastigotes within the macrophage host. Nonetheless, the ability to develop a non-toxic antileishmanial hederagenin-derivative is an important step forward for further development; medicinal chemistry and/or pharmaceutics may improve the profile of this compound to facilitate activity against the most clinically relevant, intracellular form of Leishmania.

\section{Structure activity relationships}

To further consider the hederagenin derivatives as possible anti-leishmanial therapeutics, it is important to understand the relationship between structure and activity.

In total 137 compounds have been screened for this work. Although sharing the common hederagenin core, the library 
Table 1 Further testing of molecules reaching the cut-off in the primary screen. Columns 1 and 2: compound code and class. Columns 3 and 4: secondary screen, dose response study. AMA ED 50 - effective dose to kill $50 \%$ of axenic L. mexicana amastigotes. Columns 5 and 6 : toxicity study. RAW $E D_{50}$ - effective dose to kill $50 \%$ of host macrophage (RAW 267.4); column 7: SI - selectivity index, RAW ED $50 / A_{M A} E D_{50}$. Columns 8 and 9: InMAC ED 50 - effective dose to kill $50 \%$ of amastigotes within macrophage host (RAW 267.4), infective cell assay. $95 \% \mathrm{Cl}-95 \%$ confidence interval; ND - not determined as values too wide. Green - selected compounds. Red - compounds excluded on basis of toxicity

\begin{tabular}{|c|c|c|c|c|c|c|c|c|}
\hline Compound & Class & $\operatorname{AMA~ED}_{50}(\mu \mathrm{M})$ & $95 \% \mathrm{Cl}$ & $\operatorname{RAW~ED}_{50}(\mu \mathrm{M})$ & $95 \% \mathrm{Cl}$ & SI & InMAC ED $D_{50}(\mu M)$ & $95 \% \mathrm{Cl}$ \\
\hline MC-033 & 6 & 0.9 & $0.47-0.71$ & 5.4 & 6.37-7.17 & 6.0 & & \\
\hline IVL-1 & 7 & 2.3 & $0.82-6.26$ & $>100$ & ND & $>44$ & $>50$ & ND \\
\hline IVL-17 & 2 & 4.5 & $0.43-8.73$ & 29.6 & ND & 6.7 & & \\
\hline IVL-106 & 3 & 6.0 & $3.79-9.54$ & 29.7 & ND & 5.0 & & \\
\hline IVL-81 & 2 & 7.2 & $5.24-9.87$ & 11.1 & ND & 1.5 & & \\
\hline IVL-16 & 3 & 7.5 & $5.65-10.7$ & 36.7 & ND & 4.9 & & \\
\hline IVL-18 & 2 & 9.5 & $8.42-10.73$ & 10.2 & ND & 1.1 & & \\
\hline IVL-9 & 1 & 9.6 & $8.49-10.8$ & 36.6 & ND & 3.8 & & \\
\hline IVL-75 & 2 & 9.7 & $9.38-10.0$ & 29.2 & ND & 3.0 & & \\
\hline MC-071 & 5 & 10.0 & $8.61-11.5$ & 4.8 & 4.37-5.37 & 0.5 & & \\
\hline IVL-104 & 3 & 10.3 & $8.98-11.8$ & 30.2 & ND & 2.9 & & \\
\hline MC-057 & 6 & 10.4 & $7.71-14.0$ & 10.9 & ND & 1.0 & & \\
\hline IVL-21 & 4 & 12.0 & $3.17-45.3$ & & & & & \\
\hline IVL101 & 3 & 13.9 & $11.2-17.29$ & & & & & \\
\hline IVL-78 & 1 & 14.6 & $11.8-18.1$ & & & & & \\
\hline IVL-24 & 3 & 14.9 & $8.18-27.1$ & & & & & \\
\hline IVL-68 & 4 & 15.1 & $6.07-37.7$ & & & & & \\
\hline MC-055 & 6 & 15.3 & $10.7-33.9$ & & & & & \\
\hline MC-108 & 6 & 17.5 & ND & & & & & \\
\hline MC-106 & 6 & 17.5 & $6.44-47.3$ & & & & & \\
\hline IVL-56 & 4 & 17.8 & ND & & & & & \\
\hline MC-059 & 6 & 19.0 & $10.6-33.9$ & & & & & \\
\hline IVL-4 & 3 & 19.2 & ND & & & & & \\
\hline MC-114 & 6 & 19.3 & 9.71-38.9 & & & & & \\
\hline IVL-72 & 3 & 19.4 & $14.3-26.1$ & & & & & \\
\hline MC-024 & 6 & 19.6 & $16.5-23.4$ & & & & & \\
\hline IVL-11 & 1 & 19.6 & ND & & & & & \\
\hline MC-118 & 6 & 19.9 & ND & & & & & \\
\hline MC-098 & 6 & 20.2 & $13.0-31.2$ & & & & & \\
\hline MC-048 & 6 & 20.9 & ND & & & & & \\
\hline IVL-74 & 2 & 21.2 & 21.1-37.0 & & & & & \\
\hline IVL-71 & 3 & 21.7 & ND & & & & & \\
\hline IVL-23 & 4 & 22.7 & $9.82-52.3$ & & & & & \\
\hline MC-092 & 6 & 26.2 & $6.65-103.5$ & & & & & \\
\hline MC-084 & 6 & 26.4 & ND & & & & & \\
\hline IVL-77 & 2 & 26.9 & ND & & & & & \\
\hline MC-097 & 6 & 32.4 & ND & & & & & \\
\hline IVL-54 & 4 & 36.2 & 3.33-394 & & & & & \\
\hline MC-093 & 6 & 37.6 & 16.1-87.9 & & & & & \\
\hline IVL-40 & 4 & 43.6 & $2.29-831$ & & & & & \\
\hline IVL-57 & 4 & 45.9 & ND & & & & & \\
\hline MC-028 & 6 & $>50$ & ND & & & & & \\
\hline MC-043 & 6 & $>50$ & ND & & & & & \\
\hline MC-046 & 6 & $>50$ & ND & & & & & \\
\hline MC-095 & 6 & $>50$ & ND & & & & & \\
\hline MC-096 & 6 & $>50$ & ND & & & & & \\
\hline IVL-22 & 4 & $>50$ & ND & & & & & \\
\hline IVL-53 & 4 & $>50$ & ND & & & & & \\
\hline IVL-73 & 3 & $>50$ & ND & & & & & \\
\hline IVL-80 & 2 & $>50$ & ND & & & & & \\
\hline IVL-58 & 4 & $>50$ & ND & & & & & \\
\hline IVL-19 & 2 & $>50$ & ND & & & & & \\
\hline IVL-90 & 2 & $>50$ & ND & & & & & \\
\hline IVL-105 & 5 & $>50$ & ND & & & & & \\
\hline IVL-12 & 1 & $>50$ & ND & & & & & \\
\hline IVL-100 & 4 & $>50$ & ND & & & & & \\
\hline IVL-13 & 1 & $>50$ & ND & & & & & \\
\hline IVL-5 & 4 & $>50$ & ND & & & & & \\
\hline
\end{tabular}

is diverse and can be broadly divided into 8 subgroups according to functionalities. These the groups are: the natural products, including the hederosides (group 1), the anemoclemosides (2), other 3,23-hederagenin acetals (3), the hederagenin esters (4), compounds in which both the acid and the diol are protected (as esters and acetals respectively) - protected hederagenins (5), the ureas (6), the triacids (7), and a small number non-classified derivatives, principally intermediates to the synthesis of other compounds (8). Representative results for the various groups are summarised as follows:

1. Natural products. While all semi-synthetic molecules studied were based on the major sapogenin core of Hedera helix, hederagenin (IVL-7), 8 other compounds in the library were natural products. In the primary screen, hederagenin (IVL-7) inhibited amastigote proliferation below the threshold 


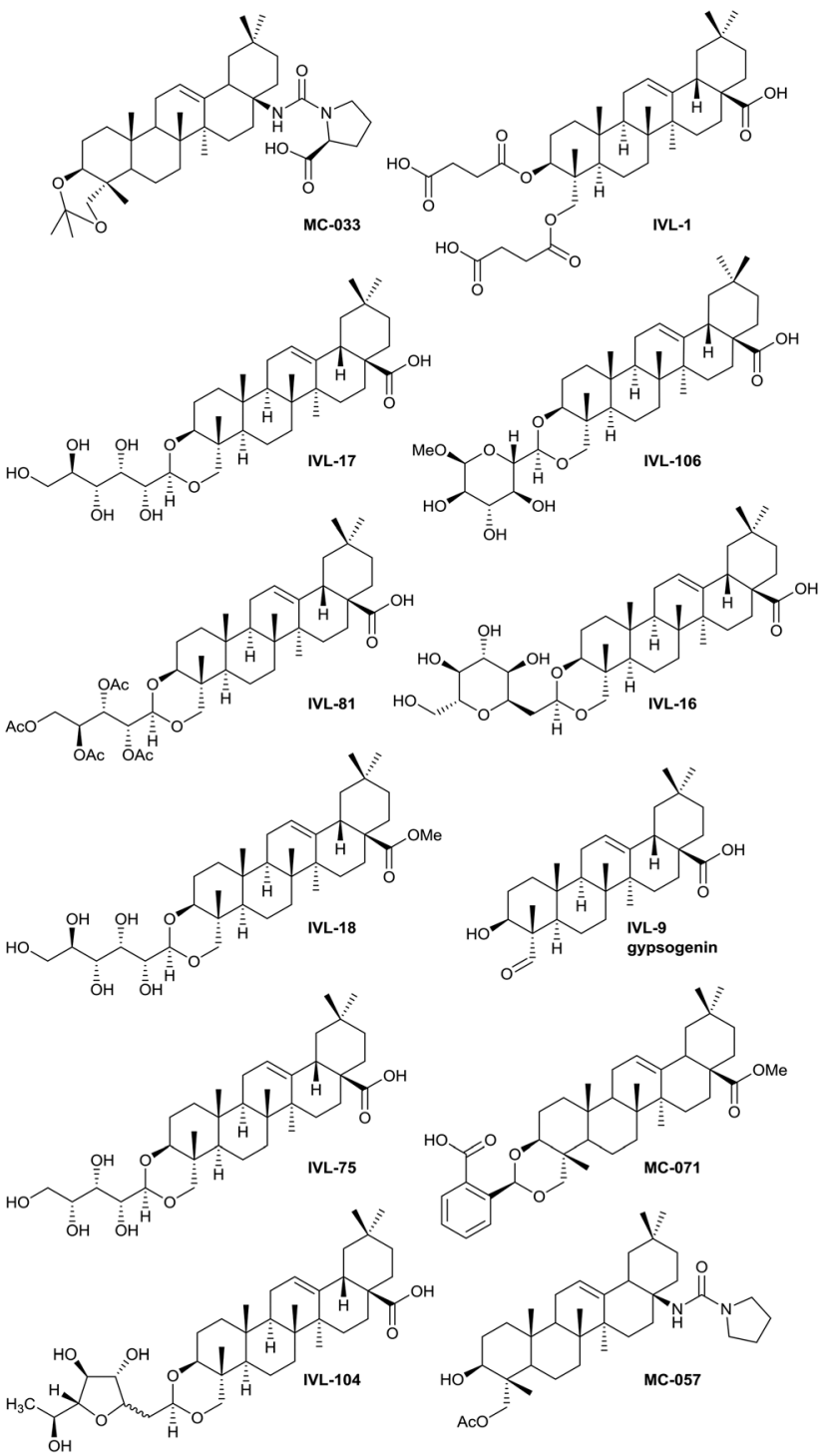

Fig. 3 Hit compound structures selected from dose response study.

(95\%), whereas many of the modified molecules were active (inhibition $\geq 95 \%$; Table $\mathrm{S} 1 \dagger$ ). Oleanolic acid (IVL-8), a minor sapogenin in Hedera helix lacking the C-26 hydroxy group compared to hederagenin, was also deselected (Table S1†). In contrast, another minor sapogenin, gypsogenin (IVL-9), was a selected inhibitor and was carried through the three screening stages of the study (Fig. 2 and 3 and Table 1). The aglycone gypsogenin is closely related to $\alpha$-hederin (IVL-11), having the primary alcohol at C-26 oxidized to an aldehyde. The natural ivy saponins $\alpha$-hederin (IVL-11) and $\delta$-hederin (IVL-13) both reached the cut-off in the primary analyses (inhibition $\geq 95 \%$, Table $\mathrm{S} 1 \dagger$ ); however, the $\mathrm{ED}_{50}$ values were too high $(>10 \mu \mathrm{M})$ in the secondary dose response screen to warrant further evaluation (Fig. 2 and Table 1). In the primary screen (Table $\mathrm{S} 1 \dagger$ ), the monodesmoside hederoside B (IVL-12) was also found to be a good inhibitor $(\geq 95 \%$ inhibition), whilst hederoside F (IVL-14) did not reach this cut-off and the bidesmosidic hederacoside D (IVL-15) showed no inhibition at all. The unusual saponin anemoclemoside A (IVL-78), ${ }^{79}$ comprised of hederagenin linked to an open chain sugar (L-arabinose) through a 3,23-O-acetal linkage, showed full inhibition in the primary screen, but also did not meet the $\mathrm{ED}_{50}$ cut-off in the secondary dose response screen (Fig. 2 and Table 1).

2. Anemoclemosides. The compound library included 28 anemoclemoside derivatives (Table $\mathrm{S} 1 \dagger$ ). All incorporated a 3,23-O-acetal linkage and differed primarily in the stereochemistry of the monosaccharide building blocks incorporated during the synthesis. Nine molecules in this group, all with unprotected sugar residues and thus closely resembling natural saponins, reached the primary screen threshold (Fig. 2 and Table S1†). One of these, like hederagenin (IVL-7), contained the free carboxylic acid group at C28 (IVL-17), another was a methyl ester (IVL-18). Both of these met the $\mathrm{ED}_{50}$ cut-off in the secondary dose response screen (Fig. 2 and Table 1). In contrast, the compounds incorporating protecting groups on the open-chain sugar and thus deprived of the possibility of establishing hydrogenbonding based interactions, showed little activity (Table S1 $\dagger$ ). In light of this, surprisingly, the penta-acetate IVL-81 was a complete inhibitor (100\%) in the primary screen and exceeded the cut-off in the secondary screen.

3. 3,23-Hederagenin acetals. A third group of 15 compounds in the library incorporated other 3,23-acetals of hederagenin. Nine were taken through to the secondary screening (Fig. 2 and Table 1). Acetals of simple aldehydes were poor inhibitors in the primary screen. However, as seen for the anemoclemoside derivatives, compounds containing an acetal linkage terminating in a monosaccharide (' $\mathrm{C}$ glycosides'), and thus, closely resembling the natural saponins, were good inhibitors of parasite proliferation. Two of these derivatives, IVL-104 and IVL-106, were also active in the secondary screen (Table 1).

4. Hederagenin esters. Another group of molecules in the library (19) were simple esters of hederagenin. Whilst 12 of these were taken forward from the primary screen, none were sufficiently active in the secondary assay to be considered for toxicity screening (Fig. 2 and Table 1).

5. Protected hederagenins. Twelve compounds incorporated both a 3,23-acetal and an ester in C-28. Thus, these differed from compounds in group 3 by not having a free carboxylic acid group at C-28, and so had lost a highly polar group. Only two in this group passed the primary screen. One of these, IVL-105, linked through an acetal to a glycoside, did not pass the secondary screen, whilst the other, MC-071, incorporating a free acid on the acetal protecting group allowing polar interactions, was taken forward into the final toxicity screen. Seven of this group showed no activity at all in the primary screen (Fig. 2 and Table 1).

6. Ureas. The largest group (46 derivatives) in the library were urea derivatives, produced by conversion of the acid group of hederagenin into an isocyanate followed by amine addition. Twenty of these derivatives were taken forward to the secondary screen (Fig. 2 and Table 1). Two passed the 
threshold for further evaluation, and one (MC-033), a proline derivative incorporating a free acid group, was the most active molecule in the library $\left(\mathrm{ED}_{50} \quad 0.9 \mu \mathrm{M}\right)$, but also demonstrated host toxicity (Table 1).

7. The tri-acids. This subgroup contained only one member, IVL-1, the disuccinate of hederagenin and structurally a tri-acid. Whilst not one of the highest ranking molecules in the primary screen, it passed the secondary screen threshold and was the molecule that demonstrated the least toxicity by far (Table 1). As such it was the only molecule selected for the infected cell assay (Fig. 2 and Table 1).

8. Non-classified derivatives. This group included just seven compounds, primarily intermediates in the preparation of other library members. None reached the threshold in the primary assay (Table 1).

Most of the natural saponins evaluated in this study reached the cut-off point in the primary screen, however only gypsogenin (IVL-9) was taken forward following secondary screening. It is the only aldehyde in the compound library, which may explain its efficacy, and its toxicity (Table 1). As observed for other saponins, its bioactivity as an antiinflammatory and cytotoxic compound has been associated with the presence of the carbohydrate component. ${ }^{78}$ However, gypsogenin has also been demonstrated to trigger the apoptotic pathway in cancer cells. ${ }^{79}$ Of the synthetically modified hederagenins, three types were most active antileishmanial: group 6 - a urethane modification in position $\mathrm{C}$ 28; group 2 - an acid at C-28 and a sugar moiety at C-3 and/ or $\mathrm{C}-23$, to resemble natural monodesmotic saponins; and group 7, IVL-1, with a terminal acid substituent at each of these positions.

Saponins are well known to disrupt membranes through the interaction with sterols. ${ }^{80}$ As such, the amphiphilicity and the stereochemistry introduced by saccharide moieties may be of importance. An overall trend was that removal of polarity from both sides of the aglycone (the C-3, C-26 and C-28 positions) reduced the anti-leishmanial efficacy. Interestingly, the bidesmosidic natural compound hederacoside D (IVL-15) was inactive, suggesting that a balanced distribution of polarity over the saponin is important. While some C-28 esters passed the primary screen cut-off, only the saponin-like methyl ester (e.g. IVL-18) was selected after the secondary assay. The C-28 methyl ester incorporating a carboxylic acid group on the C-3,23 acetal (MC-071), was also selected. Conversely, reducing position C-28 to the corresponding alcohol (MC-029) resulted in low activity (below primary screen threshold). An interesting group of compounds in this context are the xylose based anemoclemosides analogues. Whilst the C-28 acids IVL-17 and IVL-75 were carried through to the final screes, then excluded by virtue of low selectivity (SI 6.7 and 3.0 respectively), the corresponding C-28 alcohol IVL-90 failed at the secondary assay stage. The C-28 methyl ester IVL-89 was excluded after primary screening. This demonstrated that the loss of the acid group in C-28 could not be compensated by keeping an unprotected sugar unit on the C3, C23 position, indicating that subtle variations in the structure could be relevant. There was at least some link between activity and stereochemistry in that only a minority of the cyclised compounds derived from xylose (e.g. IVL-106) reached the primary screen threshold, compared to the glucosyl, arabinosyl and rhamnosyl derivatives. In general, the anemoclemosides resemble the natural monodesmosides such as the $\alpha$ - and $\delta$-hederins, with some added flexibility due to the open chain presentation of the sugar moiety, and anti-leishmanial activity is at least partly dependent on amphiphilicity and the stereochemistry introduced by saccharide moieties. Against this background, the activity of IVL-81, in which the sugar was protected as a tetra-acetate, is surprising and indicated that there could be subtle reasons for anemoclemoside anti-leishmanial activity.

A large number of the library members (46) contained the urea unit, a well-established 'drug-like' pharmacore, and most of these were active in the primary screen (Table S1†). It is interesting to note that the one with the lowest $\mathrm{ED}_{50}(\mathbf{M C}$ 033) was the only example to have a free acid substituent on the urea (Fig. 3).

\section{Conclusions}

Given the paucity of safe and effective therapies for CL, and a rising number of cases in an increasing geographic area, the search for novel anti-leishmanials is as urgent as ever. Reflecting the absence of fully validated and assay formulated targets in these parasites, the focus has been on phenotypic screening for new lead compounds. ${ }^{81}$ Natural product discovery forms part of this global effort and novel antileishmanials from these sources are discovered almost always as a result of target-blind screening. ${ }^{16,17,28}$

Novel triterpenoid saponins isolated from Maesa argentea leaves whilst active against infective stage $L$. infantum were also cytotoxic at a similar range. ${ }^{39}$ Whilst consideration of delivery mechanisms may mitigate against toxicity, ${ }^{51}$ other triterpenoid saponins have more promising profiles. For example, maesabalide II, again from isolated Maesa argentea leaves, demonstrated potent and specific anti-leishmanial $(L$. infantum) activity and promising in vivo activity. ${ }^{41,42}$ Furthermore, triterpenoid saponins isolated from Careya arborea leaves ${ }^{44}$ and the lower stem parts of Astragalus oleifolius $^{48}$ showed specific activity against infective stage $L$. donovani. Together these data indicated that triterpenoid saponins (including hederagenins) may be a source of drug leads from leishmaniasis. However, in many cases these natural products are isolated in small quantities and only after a significant effort separating them from other components. In contrast, hederagenin can be readily isolated from Hedera helix (common ivy) in large quantities and in this study we utilized a phenotypic screening approach to identify anti-leishmanial semi-synthetic triterpenoid saponins based on hederagenin.

The most selective (non-toxic to the mammalian macrophage host cell) anti-leishmanial compound, IVL-1, 
structurally differs substantially from all other 136 compounds in the library screened. This tri-acid, the disuccinate of hederagenin, is known to be active in improving the growth of ruminants, ${ }^{82}$ and it and its salts have been reported to have value as anti-depressant drugs. ${ }^{83}$ It will be of interest therefore to further evaluate the efficacy of this molecule and examine other di- or tri-acidic species. It is also of interest to determine whether the presence of three acid groups have a specific effect on its bioavailability. However, to facilitate further development IVL-1 must be developed to show activity against the parasites when they are residing with the host cell (intra-macrophage). The use of both liposomal and nano-particle formulations have been shown to improve efficacy of natural product antileishmanials and it is feasible that either or both of these approaches may facilitate the uptake of IVL-1 into the macrophage as well as improving bioavailability. ${ }^{16,84-86}$ Subsequently, to aid rational development towards the clinic, an understanding of the mode of action is vital. ${ }^{87-90}$ Mass spectrometry-based metabolomics has been applied to investigate this for both clinical drugs and experimental natural compounds, although the results of these studies can be difficult to interpret. ${ }^{28,91}$

Notably all but one, the natural cyclic peptide amphotericin B, of the current clinical anti-leishmanials lacks a well-defined mechanism of action. ${ }^{16,91}$ Mammalian cells harbour cholesterol as the primary sterol, in contrast fungi and Leishmania spp possess ergosterol. ${ }^{91}$ This difference is exploited for both anti-fungal and antileishmanial therapy by amphotericin B which selectively sequesters ergosterol. ${ }^{91}$ Following this precedent, saponins are known to disrupt membranes via interaction with sterols $^{80}$ and, like amphotericin $\mathrm{B}$, the selective nature of IVL-1 may be due to the presence of ergosterol rather than cholesterol in the plasma membrane of Leishmania. This requires further investigation and, notably, amphotericin B resistant Leishmania have been selected and demonstrated by whole genome sequencing to harbour mutations in the ergosterol biosynthetic pathway. ${ }^{92,93}$ Similar analyses could, in future, reveal the mode of action of the highly selective disuccinate of hederagenin, IVL-1.

\section{Conflicts of interest}

There are no conflicts to declare.

\section{Acknowledgements}

The research leading to these results has, in part, received funding from UK Research and Innovation via the Global Challenges Research Fund under grant agreement 'A Global Network for Neglected Tropical Diseases' grant number MR/ P027989/1. The compounds studied in this work were prepared as part of an IUK grant (102101). EJW, JHO, RMW and AL carried out chemical synthetic work as undergraduates at Bangor University. All the biological experimentation was carried out by OA, JB, CCB, LAN and CFC when they were undergraduate students at Durham University.

\section{References}

1 WHO, https://www.who.int/leishmaniasis/en/, 2019.

2 K. Stuart, R. Brun, S. Croft, A. Fairlamb, R. E. Gurtler, J. McKerrow, S. Reed and R. Tarleton, J. Clin. Invest., 2008, 118, 1301-1310.

3 R. Reithinger, J. C. Dujardin, H. Louzir, C. Pirmez, B. Alexander and S. Brooker, Lancet Infect. Dis., 2007, 7, 581-596.

4 S. Burza, S. L. Croft and M. Boelaert, Lancet, 2018, 392, 951-970.

5 S. Khare, A. S. Nagle, A. Biggart, Y. H. Lai, F. Liang, L. C. Davis, S. W. Barnes, C. J. Mathison, E. Myburgh, M. Y. Gao, J. R. Gillespie, X. Liu, J. L. Tan, M. Stinson, I. C. Rivera, J. Ballard, V. Yeh, T. Groessl, G. Federe, H. X. Koh, J. D. Venable, B. Bursulaya, M. Shapiro, P. K. Mishra, G. Spraggon, A. Brock, J. C. Mottram, F. S. Buckner, S. P. Rao, B. G. Wen, J. R. Walker, T. Tuntland, V. Molteni, R. J. Glynne and F. Supek, Nature, 2016, 537, 229-233.

6 I. Pena, M. Pilar Manzano, J. Cantizani, A. Kessler, J. AlonsoPadilla, A. I. Bardera, E. Alvarez, G. Colmenarejo, I. Cotillo, I. Roquero, F. de Dios-Anton, V. Barroso, A. Rodriguez, D. W. Gray, M. Navarro, V. Kumar, A. Sherstnev, D. H. Drewry, J. R. Brown, J. M. Fiandor and J. Julio Martin, Sci. Rep., 2015, 5, 8771.

7 J. L. Norcliffe, J. G. Mina, E. Alvarez, J. Cantizani, F. de Dios-Anton, G. Colmenarejo, S. G. Valle, M. Marco, J. M. Fiandor, J. J. Martin, P. G. Steel and P. W. Denny, Sci. Rep., 2018, 8, 3938.

8 S. L. Croft and G. H. Coombs, Trends Parasitol., 2003, 19, 502-508.

9 L. Kedzierski, A. Sakthianandeswaren, J. M. Curtis, P. C. Andrews, P. C. Junk and K. Kedzierska, Curr. Med. Chem., 2009, 16, 599-614.

10 F. Chappuis, S. Sundar, A. Hailu, H. Ghalib, S. Rijal, R. W. Peeling, J. Alvar and M. Boelaert, Nat. Rev. Microbiol., 2007, 5, 873-882.

11 C. Demicheli, R. Ochoa, J. B. da Silva, C. A. Falcao, B. RossiBergmann, A. L. de Melo, R. D. Sinisterra and F. Frezard, Antimicrob. Agents Chemother., 2004, 48, 100-103.

12 S. L. Croft, S. Sundar and A. H. Fairlamb, Clin. Microbiol. Rev., 2006, 19, 111-126.

13 P. G. Bray, M. P. Barrett, S. A. Ward and H. P. de Koning, Trends Parasitol., 2003, 19, 232-239.

14 C. P. Thakur, R. K. Singh, S. M. Hassan, R. Kumar, S. Narain and A. Kumar, Trans. R. Soc. Trop. Med. Hyg., 1999, 93, 319-323.

15 C. Di Giorgio, F. Faraut-Gambarelli, A. Imbert, P. Minodier, M. Gasquet and H. Dumon, J. Antimicrob. Chemother., 1999, 44, 71-76.

16 R. L. Charlton, B. Rossi-Bergmann, P. W. Denny and P. G. Steel, Parasitology, 2018, 145, 219-236.

17 P. E. Cockram and T. K. Smith, J. Nat. Prod., 2018, 81, 2138-2154. 
18 J. C. Aponte, D. Castillo, Y. Estevez, G. Gonzalez, J. Arevalo, G. B. Hammond and M. Sauvain, Bioorg. Med. Chem. Lett., 2010, 20, 100-103.

19 P. Boeck, C. A. Bandeira Falcao, P. C. Leal, R. A. Yunes, V. C. Filho, E. C. Torres-Santos and B. Rossi-Bergmann, Bioorg. Med. Chem., 2006, 14, 1538-1545.

20 M. Chen, S. B. Christensen, T. G. Theander and A. Kharazmi, Antimicrob. Agents Chemother., 1994, 38, 1339-1344.

21 T. F. de Mello, H. R. Bitencourt, R. B. Pedroso, S. M. Aristides, M. V. Lonardoni and T. G. Silveira, Exp. Parasitol., 2014, 136, 27-34.

22 E. R. da Silva, C. Maquiaveli Cdo and P. P. Magalhaes, Exp. Parasitol., 2012, 130, 183-188.

23 B. Mittra, A. Saha, A. R. Chowdhury, C. Pal, S. Mandal, S. Mukhopadhyay, S. Bandyopadhyay and H. K. Majumder, Mol. Med., 2000, 6, 527-541.

24 B. B. Mishra, R. K. Singh, A. Srivastava, V. J. Tripathi and V. K. Tiwari, Mini-Rev. Med. Chem., 2009, 9, 107-123.

25 D. C. Arruda, F. L. D'Alexandri, A. M. Katzin and S. R. Uliana, Antimicrob. Agents Chemother., 2005, 49, 1679-1687.

26 S. R. M. S. do Socorro, R. R. Mendonca-Filho, H. R. Bizzo, I. de Almeida Rodrigues, R. M. Soares, T. Souto-Padron, C. S. Alviano and A. H. Lopes, Antimicrob. Agents Chemother., 2003, 47, 1895-1901.

27 J. D. Dutcher, Dis. Chest, 1968, 54(Suppl 1), 296-298.

28 A. J. Mbekeani, R. S. Jones, M. Bassas Llorens, J. Elliot, C. Regnault, M. P. Barrett, J. Steele, B. Kebede, S. K. Wrigley, L. Evans and P. W. Denny, Int. J. Parasitol.: Drugs Drug Resist., 2019, 11, 118-128.

29 J. M. Augustin, V. Kuzina, S. B. Andersen and S. Bak, Phytochemistry, 2011, 72, 435-457.

30 S. T. Mugford, T. Louveau, R. Melton, X. Qi, S. Bakht, L. Hill, T. Tsurushima, S. Honkanen, S. J. Rosser, G. P. Lomonossoff and A. Osbourn, Plant Cell, 2013, 25, 1078-1092.

31 T. Moses, K. K. Papadopoulou and A. Osbourn, Crit. Rev. Biochem. Mol. Biol., 2014, 49, 439-462.

32 S. Ur Rahman, M. Ismail, M. Khurram, I. Ullah, F. Rabbi and M. Iriti, Molecules, 2017, 22, 2156.

33 B. W. Greatrex, A. M. Daines, S. Hook, D. H. Lenz, W. McBurney, T. Rades and P. M. Rendle, ChemistryOpen, 2015, 4, 740-755.

34 S. G. Sparg, M. E. Light and J. van Staden, J. Ethnopharmacol., 2004, 94, 219-243.

35 R. C. de Paula, S. M. da Silva, K. F. Faria, F. Frezard, C. P. S. Moreira, K. Foubert, J. C. D. Lopes, P. R. V. Campana, M. P. Rocha, A. F. Silva, C. G. Silva, L. Pieters and V. L. Almeida, J. Ethnopharmacol., 2019, 232, 155-164.

36 F. Delmas, C. Di Giorgio, R. Elias, M. Gasquet, N. Azas, V. Mshvildadze, G. Dekanosidze, E. Kemertelidze and P. Timon-David, Planta Med., 2000, 66, 343-347.

37 M. C. Duarte, G. S. Tavares, D. G. Valadares, D. P. Lage, T. G. Ribeiro, L. M. Lage, M. R. Rodrigues, A. A. Faraco, M. Soto, E. S. da Silva, M. A. Chavez Fumagalli, C. A. Tavares, J. P. Leite, J. S. Oliveira, R. O. Castilho and E. A. Coelho, Exp. Parasitol., 2016, 166, 21-28.
38 A. Dutta, A. Ghoshal, D. Mandal, N. B. Mondal, S. Banerjee, N. P. Sahu and C. Mandal, J. Med. Microbiol., 2007, 56, 1196-1204.

39 K. Foubert, T. Gorella, A. Faizal, P. Cos, L. Maes, S. Apers, D. Geelen and L. Pieters, Planta Med., 2016, 82, 1568-1575.

40 N. Germonprez, L. Maes, L. Van Puyvelde, M. Van Tri, D. A. Tuan and N. De Kimpe, J. Med. Chem., 2005, 48, 32-37.

41 L. Maes, N. Germonprez, L. Quirijnen, L. Van Puyvelde, P. Cos and D. Vanden Berghe, Antimicrob. Agents Chemother., 2004, 48, 2056-2060.

42 L. Maes, D. Vanden Berghe, N. Germonprez, L. Quirijnen, P. Cos, N. De Kimpe and L. Van Puyvelde, Antimicrob. Agents Chemother., 2004, 48, 130-136.

43 B. Majester-Savornin, R. Elias, A. M. Diaz-Lanza, G. Balansard, M. Gasquet and F. Delmas, Planta Med., 1991, 57, 260-262.

44 D. Mandal, N. Panda, S. Kumar, S. Banerjee, N. B. Mandal and N. P. Sahu, Phytochemistry, 2006, 67, 183-190.

45 S. M. Mohamed, E. Y. Bachkeet, S. A. Bayoumi, S. Jain, S. J. Cutler, B. L. Tekwani and S. A. Ross, Fitoterapia, 2015, 107, 114-121.

46 A. L. Moreira, D. B. Scariot, B. L. Pelegrini, G. L. Pessini, T. Ueda-Nakamura, C. V. Nakamura and I. C. P. Ferreira, Evid. Based Complement. Alternat. Med., 2017, 2017, 5620693.

47 H. A. Oketch-Rabah, S. F. Dossaji, S. B. Christensen, K. Frydenvang, E. Lemmich, C. Cornett, C. E. Olsen, M. Chen, A. Kharazmi and T. Theander, J. Nat. Prod., 1997, 60, 1017-1022.

48 M. Ozipek, A. A. Donmez, I. Calis, R. Brun, P. Ruedi and D. Tasdemir, Phytochemistry, 2005, 66, 1168-1173.

49 F. Rezaee, B. Zolfaghari and M. S. Dinani, Res. Pharm. Sci., 2018, 13, 469-475.

50 O. Ridoux, C. Di Giorgio, F. Delmas, R. Elias, V. Mshvildadze, G. Dekanosidze, E. Kemertelidze, G. Balansard and P. Timon-David, Phytother. Res., 2001, 15, 298-301.

51 H. Van de Ven, M. Vermeersch, A. Matheeussen, J. Vandervoort, W. Weyenberg, S. Apers, P. Cos, L. Maes and A. Ludwig, Int. J. Pharm., 2011, 420, 122-132.

52 A. Gepdiremen, V. Mshvildadze, H. Suleyman and R. Elias, Phytomedicine, 2005, 12, 440-444.

53 Y. Lutsenko, W. Bylka, I. Matlawska, O. Gavrylyuk, M. Dworacka, A. Krawczyk and V. Brytska, Acta Pol. Pharm., 2017, 74, 1159-1166.

54 A. Rai, Indian J. Pharm. Sci., 2013, 75, 99-102.

55 A. B. Hocaoglu, O. Karaman, D. O. Erge, G. Erbil, O. Yilmaz, B. Kivcak, H. A. Bagriyanik and N. Uzuner, Iran. J. Allergy, Asthma Immunol., 2012, 11, 316-323.

56 S. Zeil, U. Schwanebeck and C. Vogelberg, Phytomedicine, 2014, 21, 1216-1220.

57 M. Stauss-Grabo, S. Atiye, A. Warnke, R. S. Wedemeyer, F. Donath and H. H. Blume, Phytomedicine, 2011, 18, 433-436.

58 J. Song, S. G. Yeo, E. H. Hong, B. R. Lee, J. W. Kim, J. Kim, H. Jeong, Y. Kwon, H. Kim, S. Lee, J. H. Park and H. J. Ko, Biomol. Ther., 2014, 22, 41-46.

59 J. Wang, H. Deng, J. Zhang, D. Wu, J. Li, J. Ma and W. Dong, Phytother. Res., 2020, 34, 601-611. 
60 T. A. Prescott, L. P. Rigby, N. C. Veitch and M. S. Simmonds, Phytochemistry, 2014, 101, 116-120.

61 O. Rosca-Casian, C. Mircea, L. Vlase, A. M. Gheldiu, D. T. Teuca and M. Parvu, Acta Biol. Hung., 2017, 68, 196-207.

62 H. Hooshyar, S. Talari and F. Feyzi, Jundishapur J. Microbiol., 2014, 7, e9432.

63 M. S. Baird and D. Preskett, European Pat., EP2234479, 2007.

64 J. Sun, X. Han and B. Yu, Org. Lett., 2005, 7, 1935-1938.

65 G. S. R. Subba Rao, P. Kondaiah, S. K. Singh, P. Ravanan and M. B. Sporn, Tetrahedron, 2008, 64, 11541-11548.

66 X.-C. Li, C.-R. Yang, Y.-Q. Liu, R. Kasai, K. Ohtani, K. Yamasaki, K. Miyahara and K. Shingu, Phytochemistry, 1995, 39, 1175-1179.

67 D. Rouzaud and P. Sinaÿ, J. Chem. Soc., Chem. Commun., 1983, 1353-1354, DOI: 10.1039/C39830001353.

68 O. Cortezano-Arellano, C. A. Meléndez-Becerra, F. Cortés, F. Sartillo-Piscil and A. Cordero-Vargas, Carbohydr. Res., 2014, 393, 51-59.

69 H. I. Ciftci, S. E. Ozturk, T. F. S. Ali, M. O. Radwan, H. Tateishi, R. Koga, Z. Ocak, M. Can, M. Otsuka and M. Fujita, Biol. Pharm. Bull., 2018, 41, 570-574.

70 F. L. Chadbourne, C. Raleigh, H. Z. Ali, P. W. Denny and S. L. Cobb, J. Pept. Sci., 2011, 17, 751-755.

71 J. H. Zhang, T. D. Chung and K. R. Oldenburg, J. Biomol. Screening, 1999, 4, 67-73.

72 H. L. Bolt, G. A. Eggimann, P. W. Denny and S. L. Cobb, MedChemComm, 2016, 7, 799-805.

73 S. L. Cobb and P. W. Denny, Curr. Opin. Invest. Drugs, 2010, 11, 868-875.

74 G. A. Eggimann, H. L. Bolt, P. W. Denny and S. L. Cobb, ChemMedChem, 2015, 10, 233-237.

75 G. A. Eggimann, K. Sweeney, H. L. Bolt, N. Rozatian, S. L. Cobb and P. W. Denny, Molecules, 2015, 20, 2775-2785.

76 L. M. Alcantara, T. C. S. Ferreira, F. R. Gadelha and D. C. Miguel, Int. J. Parasitol.: Drugs Drug Resist., 2018, 8, 430-439.

77 M. De Rycker, I. Hallyburton, J. Thomas, L. Campbell, S. Wyllie, D. Joshi, S. Cameron, I. H. Gilbert, P. G. Wyatt, J. A. Frearson, A. H. Fairlamb and D. W. Gray, Antimicrob. Agents Chemother., 2013, 57, 2913-2922.

78 M. Wang, Z. Zhan, Y. Xiong, Y. Zhang and X. Li, Fitoterapia, 2019, 139, 104360.
79 S. Emirdağ-Öztürk, T. Karayıldırım, A. Çapcı-Karagöz, Ö. Alankuş-Çalışkan, A. Özmen and E. Poyrazoğlu-Çoban, Eur. J. Med. Chem., 2014, 82, 565-573.

80 M. C. Jamur and C. Oliver, Methods Mol. Biol., 2010, 588, 63-66.

81 I. Pena, M. P. Manzano, J. Cantizani, A. Kessler, J. AlonsoPadilla, A. I. Bardera, E. Alvarez, A. Rodriquez, D. W. Gray, M. Navarro, V. Kumar, A. Shaerstnev, D. H. Drewry, J. R. Brown, J. M. Fiandor and J. J. Martin, Sci. Rep., 2015, 5, 8771.

82 B. Radek, C. Wehrli, D. Preskett, M. E. Bouillon, S. Duval, M. E. Ramos, J. R. Al-dulayymi, C. J. Newbold, S. W. Strawson, M. Baird and M. Lahmann, Patent, WO2016193309A1, 2016.

83 R. Ma, Q. Shi, R. Zhou, Q. Zhou and J. Huang, Patent, WO2013174245A1, 2012.

84 C. B. de Mattos, D. F. Argenta, L. Melchiades Gde, M. N. Cordeiro, M. L. Tonini, M. H. Moraes, T. B. Weber, S. S. Roman, R. J. Nunes, H. F. Teixeira, M. Steindel and L. S. Koester, Int. J. Nanomed., 2015, 10, 5529-5542.

85 E. C. Torres-Santos, J. M. Rodrigues, Jr., D. L. Moreira, M. A. Kaplan and B. Rossi-Bergmann, Antimicrob. Agents Chemother., 1999, 43, 1776-1778.

86 D. O. Escrivani, M. V. Lopes, F. Poletto, S. R. Ferrarini, A. J. Sousa-Batista, P. G. Steel, S. S. Guterres, A. R. Pohlmann and B. Rossi-Bergmann, Nanomedicine, 2020, 24, 102121.

87 P. W. Denny, Expert Opin. Drug Discovery, 2018, 13, 1153-1160.

88 P. W. Denny, Parasitology, 2018, 145, 111-115.

89 P. W. Denny and P. G. Steel, J. Biomol. Screening, 2015, 20, 56-63, [pii].

90 J. L. Norcliffe, E. Alvarez-Ruiz, J. J. Martin-Plaza, P. G. Steel and P. W. Denny, Parasitology, 2014, 141, 8-16.

91 E. G. Armitage, A. Q. I. Alqaisi, J. Godzien, I. Pena, A. J. Mbekeani, V. Alonso-Herranz, A. Lopez-Gonzalvez, J. Martin, R. Gabarro, P. W. Denny, M. P. Barrett and C. Barbas, Antimicrob. Agents Chemother., 2018, 62, e02095-e02117.

92 R. Mwenechanya, J. Kovarova, N. J. Dickens, M. Mudaliar, P. Herzyk, I. M. Vincent, S. K. Weidt, K. E. Burgess, R. J. S. Burchmore, A. W. Pountain, T. K. Smith, D. J. Creek, D. H. Kim, G. I. Lepesheva and M. P. Barrett, PLoS Neglected Trop. Dis., 2017, 11, e0005649.

93 A. W. Pountain, S. K. Weidt, C. Regnault, P. A. Bates, A. M. Donachie, N. J. Dickens and M. P. Barrett, PLoS Neglected Trop. Dis., 2019, 13, e0007052. 